https://doi.org/10.15407/ujpe63.4.339

I.P. ILCHYSHYN, E.A. TIKHONOV, T.V. MYKYTIUK

Institute of Physics, Nat. Acad. Sci. of Ukraine

(46, Nauky Ave., Kyiv 03028,Ukraine; e-mail: lclas@iop.kiev.ua)

\title{
SPECTRAL AND SPATIAL FEATURES OF RADIATION EMITTED BY A CHOLESTERIC LIQUID-CRYSTAL LASER ${ }^{1}$
}

\begin{abstract}
Spectral and spatial characteristics of radiation emitted by a laser operating on the Bragg structure arising in cholesteric liquid crystals (CLCs) have been studied, as well as their variations with a change of the planar $C L C$ orientation. A defect in the helical structure of the CLC formed by a ternary mixture of cholesterol viscous esters is revealed at the mutually orthogonal orientations of the $C L C$ director at the substrates. This defect manifests itself as a local dip in the selective reflection band, which agrees with the behavior of the defect mode in the photonic crystal. Such a defect in the helical structure stimulates the selection of longitudinal modes with the indices $N= \pm 1$, so that the single-mode lasing regime is realized. A spatial ring structure in the laser radiation is found to arise, when higher longitudinal modes are generated.

Ke y words: cholesteric liquid crystal, planar texture, lasing spectra, spatial mode structure.
\end{abstract}

\section{Introduction}

Dye-doped cholesteric liquid crystals (CLCs) with a natural periodic structure have been known in laser physics for a long time [1,2]. Besides the formation of an optical resonator, the main advantage of such naturally structured material is a possibility to construct a laser, whose active medium has an arbitrary area and curvature. Such lasers are promising, in particular, for the development of high-brightness displays, which are capable of displaying information under bright light conditions.

The ideas concerning the lasing origin in the examined structures were first developed exclusively on the basis of the distributed-feedback (DF) laser model $[3,4]$. Later, the consideration was extended onto the model of photonic crystals $[5,6]$, which gave an answer to the question why the generation spectrum of nematics with induced helix is located at the edge of the selective reflection (SR) band of CLCs [7-9] rather than at its center, where the reflectance is maximum. The analysis of the relation between these models of lasing in CLC lasers according to the "photonic crystal strength", which is determined by the birefringence magnitude, was carried out in review [10]. It should be noted that the phenomenon of pho-

(C) I.P. ILCHYSHYN, E.A. TIKHONOV,

T.V. MYKYTIUK, 2018

ISSN 2071-0194. Ukr. J. Phys. 2018. Vol. 63, No. 4 ton localization in a periodic structure of CLC, which manifests itself in the fluorescence quenching at SR frequencies in the direction along the helix axis as the specific feature of a one-dimensional photonic crystal, was first registered in our works $[1,2]$ together with the lasing effect.

CLC lasers as elements of modern bright displays are actively studied at many research centers. Nowadays, a number of significant results concerning the generation in new CLC materials [11-13], the expansion of lasing frequency intervals [14], and the research of CLC energy parameters $[15,16]$ have been obtained. The results of modern achievements in the CLC-laser domain were discussed in the recent reviews [10, 17-19].

In the recent years, CLCs with defects in their helix structure have been intensively studied. Those defects result in the appearance of defect modes in the forbidden gap. As a defect, it can be a violation of the CLC helix phase, the arrangement of any isotropic medium between two CLC layers with a uniform helical pitch, a local change of the CLC helical pitch value, the appearance of the pitch gradient for the cholesteric helix, and so forth. The modern theory of

1 The paper was presented at the XXIII Galyna Puchkovska International School-Seminar "Spectroscopy of Molecules and Crystals". 
<smiles>CC(C)C=CC(C)C1CC2C3CC=C4CC(Cl)CCC4(C)C3CCC2(C)C1</smiles><smiles>CCOC1CCC2(C)C(=CCC3C4CC(C(C)CCC(C)C)CC4(C)CCC32)C1</smiles><smiles>COC1CCC2(C)C(=CCC3C4CC(C(C)CCC(C)C)CC4(C)CCC32)C1</smiles>

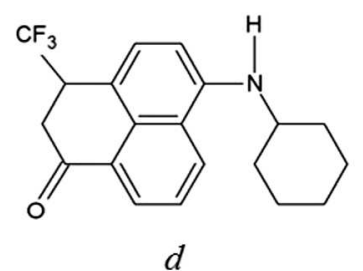

Fig. 1. Chemical structure of the substances used: cholesteryl chloride $(a)$, cholesteryl pelargonate $(b)$, cholesteryl oleate $(c)$, and phenolene dye F490 $(d)$

the lasing in photonic CLCs predicts that, for defects of some types in the helix structure and depending on the ratio between the defect layer thickness and the total CLC thickness, one or more dips can appear in the SR spectrum, which governs the frequencies of those "defect" lasing modes within the SR band [20].

Owing to a small value of the "thickness/width" ratio for the active layer, the radiation emitted by a CLC laser is characterized by a large angular divergence (tens of degrees), which has a non-diffraction origin. This ratio is also responsible for a wide lasing spectrum, even in the case of lowest longitudinal modes. The available interpretations of a ring structure arising in the beams generated by a CLC laser remain questionable. The influence of the planar texture quality on the generation characteristics of a CLC laser also requires to be studied further.

Hence, the aim of this research was to study the relationship between the spectral and spatial characteristics of the CLC laser radiation, on the one hand, and the types of director orientation at the orienting substrates, on the other hand, as well as the influence of the planar texture quality on the lasing parameters.

\section{Experimental Part}

A ternary mixture of cholesterol esters with a composition of $40 \%$ of cholesteryl oleate, $35 \%$ of cholesteryl pelargonate, and $25 \%$ of cholesteryl chloride was used as a CLC matrix. The temperatureinduced change of the corresponding helical pitch was about $3 \mathrm{~nm} /{ }^{\circ} \mathrm{C}$. The CLC mixture was doped with phenolenone dye F490 to a concentration of
0.3 wt.\%. The structural formulas of the cholesterol derivatives and the dye are depicted in Fig. 1.

The CLC mixture had a left-helical twist with the $\mathrm{SR}$ band maximum at about $600 \mathrm{~nm}$. The birefringence in the ternary mixture of cholesterol esters was about 0.04 . If necessary, the SR band could be shifted with respect to the dye fluorescence band by varying the concentrations of mixture components.

The thickness of the dye-doped cholesteric layer in the oriented specimen with a planar texture was $45 \mu \mathrm{m}$. The planar texture was created following the standard technology. The mixture of cholesterol esters has a high viscosity: in practice, this is a jelly-like suspension. Therefore, for its orientation, besides structure-oriented substrates themselves, we used their relative shift in the scraping direction [21]. The technology includes the scraping of glass substrates covered with the layer of a transparent electrode (ITO) and polyimide varnish (PIV). After the specimen had been filled, the shift in the scraping direction was carried out at a temperature close to the phase transition one. In time of creating textures with the orthogonal orientations of the CLC director at the substrates, the specimen was cooled down to the mesophase temperature, and the substrates were not shifted, but one of them was rotated by an angle of about $90^{\circ}$.

The lasing parameters were studied on a typical experimental installation. The optical pumping of a CLC laser was carried out using the second harmonic $(\lambda=530 \mathrm{~nm})$ of a neodymium-glass laser with $\mathrm{Q}$ modulation and a pulse duration of about $20 \mathrm{~ns}$. The pumping radiation was focused on a cell with a pla-

ISSN 2071-0194. Ukr. J. Phys. 2018. Vol. 63, No. 4 
narly oriented doped CLC into a spot $\sim 0.5 \mathrm{~mm}$ in diameter, so that the diameter/thickness ratio was about 11.0. The energy of a pump pulse was varied using neutral light filters and monitored with the help of an IMO-2 calorimeter. The calculated maximum of the pump intensity was about $27 \mathrm{MW} / \mathrm{cm}^{2}$.

The lasing spectra were projected onto the focal plane of a spectrograph with a reciprocal dispersion of $0.6 \mathrm{~nm} / \mathrm{mm}$ and displayed on a PC monitor with the help of a video camera. The spatial distribution of radiation emitted by the CLC laser in the near diffraction field was photographed from a matte screen. The field in the far zone was registered directly by means of a camera with a long-focus objective.

\section{Results and Their Discussion}

The analysis of the form of the transmission spectra obtained for steroid CLCs demonstrates a distinct dependence of the SR bandwidth on the planar texture quality. The best orientation was observed on substrates covered with a transparent electrode layer (ITO) [21]. The planar texture quality affected the transmission spectra, in particular, the spectral width. Figure 2 illustrates a transmission spectrum registered for an oriented CLC specimen with the planar texture and the mixture composition indicated above in the case where the orienting substrates with ITO were used.

For planar textures obtained using glass and quartz substrates covered with the transparent electrode and polyimide varnish layers, the half-width of the SR band was about $22-24 \mathrm{~nm}$ (Fig. 2). If the planar texture was formed using substrates covered only with polyimide varnish, its quality decreased significantly, which manifested itself in the broadening of the SR band by more than $10 \%$ and the diminishing of the diffraction reflection intensity (Fig. 3).

The study of lasing spectra obtained for steroid CLCs testified to their pronounced correlation with the texture quality. As is shown in Fig. 2 (the inset), the light scattering spectrum had three longitudinal modes for the texture with a narrow SR band and the parallel relative orientations of the CLC director. This spectrum was observed close to the SR band center, which corresponded to the model of coupledwave generation in a periodic structure [3]. Unlike an ordinary resonator, the growth of the excitation intensity even up to intensities, at which the specimen

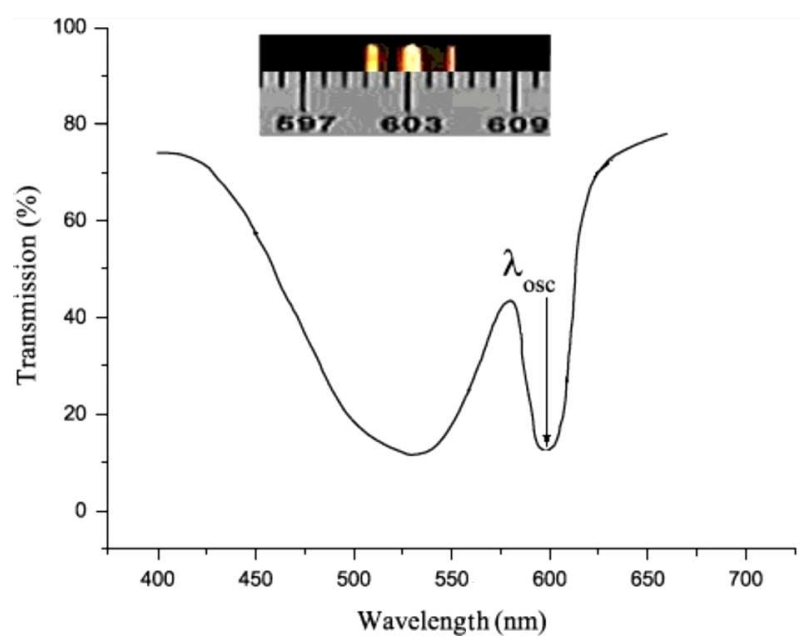

Fig. 2. Transmission spectrum of the high-quality planar texture of doped CRC. The arrow marks the location of the generation spectrum. The spectrum of the laser generation in this structure is shown in the inset. The layer thickness equals $45 \mu \mathrm{m}$

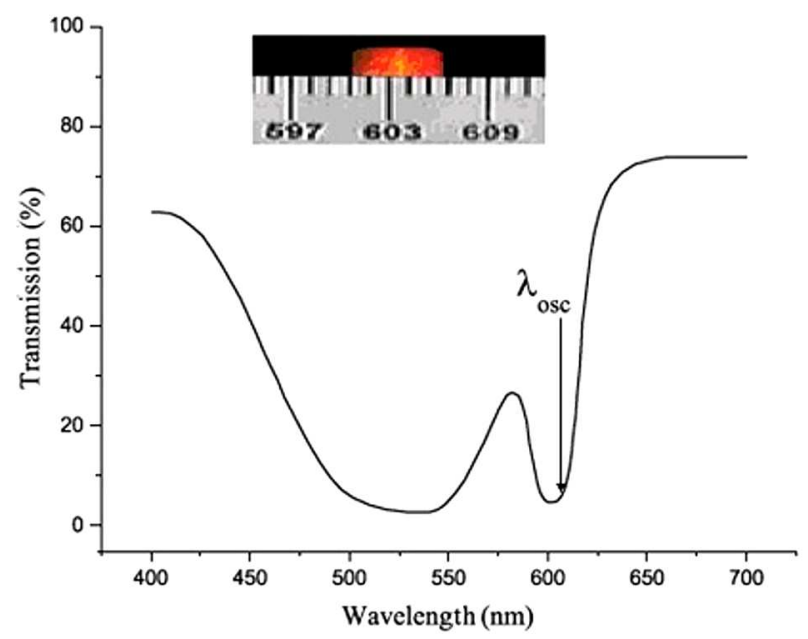

Fig. 3. Transmission spectrum of the planar texture of doped CRC formed by substrates without ITO. The arrow marks the location of the generation spectrum. The spectrum of the laser generation in this structure is shown in the inset. The layer thickness equals $45 \mu \mathrm{m}$

was destroyed, did not increase the number of longitudinal modes (Fig. 4, b).

It should be noted that the presence of a transparent electrode (ITO) on the orienting substrate manifested itself only in the SR bandwidth and its diffraction efficiency. Provided similar excitation conditions, no lasing emerged beyond the SR band and under nonselective resonator conditions created by 


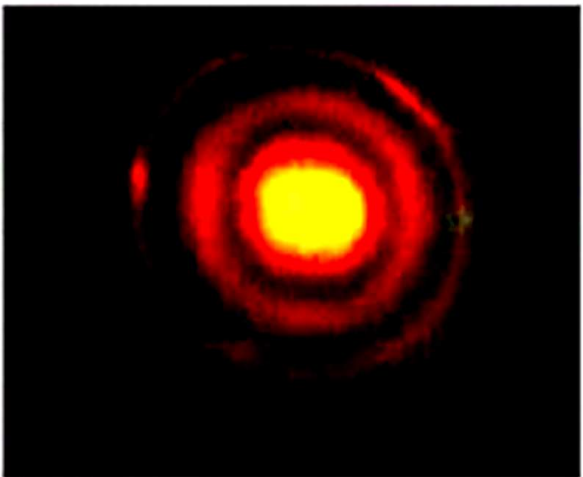

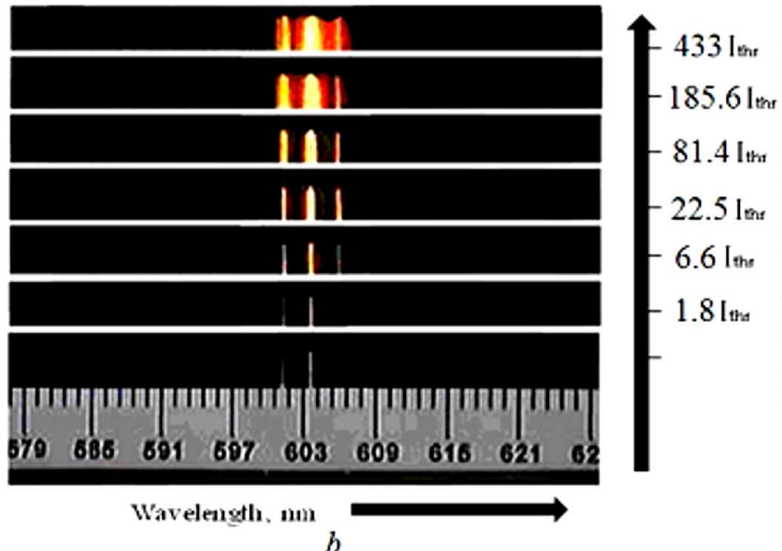

Fig. 4. Ring structure of a laser beam $(a)$ and the generation spectra of the CRC laser with parallel director orientations at the substrates $(b)$. The layer thickness equals $45 \mu \mathrm{m}$

transparent electrodes with the reflection coefficients $R=8 \div 10 \%$.

The presence of only three longitudinal modes in the laser-generation spectra obtained in the whole excitation interval testified to a high selectivity of the periodic helical structure, in accordance with the model of work [3]. It manifested itself in suppressing the generation of longitudinal modes with indices higher than $N= \pm 1$ in the CLC laser (Fig. 4, b). A similar result was obtained in work [22], when studying a DF laser on a periodic helical structure in the infrared spectral interval.

Figure 3 (the inset) demonstrates the lasing spectra for the same composition of CLC components as in Fig. 2, but for planar textures formed using substrates covered with only a polyimide varnish layer (without ITO). One can see that the lasing spectrum became slightly (by no more than $3 \mathrm{~nm}$ ) shifted from the center to the long-wave edge of the SR band, and the discrete spectral mode structure transformed into a wide diffuse band. The threshold intensity of the laser generation excitation increased substantially, by a factor of two to three, at that.

Note that, under experimental conditions and for a CLC layer thickness of $45 \mu \mathrm{m}$, the lasing thresholds of longitudinal modes with the indices $N= \pm 1$ are rather low, exceeding the lasing threshold only by about $10 \%$ for the fundamental Bragg mode. Those data were obtained, when the SR band was shifted into the fluorescence band maximum of doping dye F490 by varying the percentage composition of the applied ternary mixture of cholesterol esters. The dis- tance between the longitudinal modes in the CLC laser, as well as in a Fabry-Pérot interferometer, is equal to $\Delta \lambda \approx \lambda^{2} /(2 n L)$, where $\lambda$ is the fundamental mode wavelength, $n$ the average CLC refractive in$\operatorname{dex}$, and $L$ the active-layer thickness. At $\lambda=600 \mathrm{~nm}$, $n=1.53, L=45 \mu \mathrm{m}$, and $\Delta \lambda=2.6 \mathrm{~nm}$, the total width of the lasing spectrum is about $5.2 \mathrm{~nm}$. Under those conditions, the gain coefficient for all three modes was practically identical within the broad dye fluorescence band (Fig. 5, a). Thus, the single-mode lasing regime is practically impossible in a CLC laser based on a mixture of cholesterol esters.

A more favorable situation for the single-mode regime arises in CLC lasers with a helix induced by means of chiral dopants for nematic liquid crystals (NLCs). At the birefringence $\Delta n \geq 0.2$, which is a typical value of NLCs, the selective reflection reached almost $100 \%$, and lasing was obtained already for the active layer thickness more than $5 \mu \mathrm{m}$. The corresponding distance between the longitudinal modes was about $23 \mathrm{~nm}$, and the gain coefficients for two neighbor modes on a dye with a band half-width less than $50 \mathrm{~nm}$ were strongly different. Therefore, in lasers on induced CLCs, the single-mode lasing can be realized due to the gain selectivity and by choosing the excitation level.

In the case of standard planar orientation, a CLC laser on the ternary mixture of cholesterol esters emitted a beam with a high angular divergence. As is shown in Fig. 4, a, besides an intense central kern, a ring structure was observed with the number of rings depending on the excitation intensity. As was 

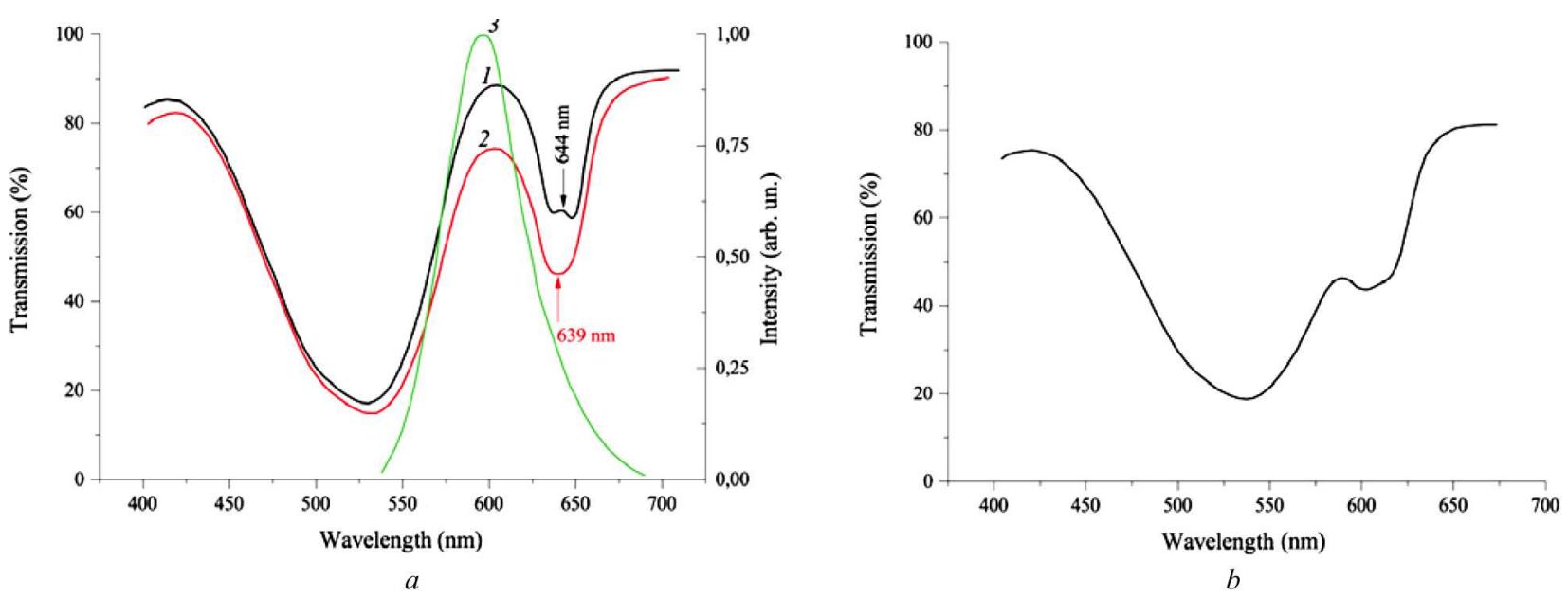

Fig. 5. $a$-transmission spectra of steroid CLCs at mutually perpendicular orientations of surface layers on the substrates (1), at parallel orientations of surface layers on the substrates (2), the fluorescence spectrum of phenolene dye F490 (3). The temperature is $26^{\circ} \mathrm{C}$. The layer thickness equals $45 \mu \mathrm{m} . \quad b$ - transmission spectrum of the mixture $38 \%$ of cholesteryl oleate, $33 \%$ of cholesteryl pelargonate, and $29 \%$ of cholesteryl chloride at mutually perpendicular orientations of surface layers on the substrates. Mixture: $38 \%$ cholesteryl oleate; $33 \%$ - cholesterol pelargonate; $29 \%$ cholesteryl chloride. The temperature is $17.5^{\circ} \mathrm{C}$. The layer thickness equals $45 \mu \mathrm{m}$

established in work [23], for an active-layer thickness of $45 \mu \mathrm{m}$, the angular radiation divergence of a CLC laser drastically increases from $1^{\circ}$ to $20^{\circ}$, when the pumping intensity exceeds the excitation threshold by more than an order of magnitude.

Today, it is widely assumed that the ring structure in the radiation of a CLC laser is a result of the radiation diffraction in a thin active layer [24]. A similar ring pattern can also emerge at the formation of an aberration heat lens due to the local laser-induced heating of absorbing layers composed of various materials [25]. In our research [23], we showed that no ring structure can arise in this geometry for the pumping beam. The time of the thermal lens formation under those conditions equals about $100 \mathrm{~ns}$, which is five times longer than the duration of the pumping and lasing pulses [26]. A possible light-induced rotation of the CLC director at the intense pumping [27] would also testify to a change of the helical pitch. In this case, a non-uniformity in the director alignment over the cross-section of the irradiated zone should result in a modification of the lasing spectrum in the rings. The research carried out in work [23] showed the invariance of generation wavelengths (to within $\pm 0.5 \mathrm{~nm}$ ) of a CLC laser - both in the central kern and in the first and second rings of the spatial laserradiation pattern - in a wide interval of excitation intensities.
In laser physics, the process of ring structure formation in the emitted radiation is associated with the radiation scattering at optical inhomogeneities in the active medium [28]. This scattering, after having been multiply reflected from the resonator mirrors, favors the formation of transverse modes. A comparison of the ring radii in the radiation beam of a CLC laser showed their agreement with the corresponding values calculated from the dependence presented in work [28]. On the basis of these data, the ring structure of the beam emitted by a CLC laser can be considered as the transverse modes of a Bragg resonator formed owing to the scattering of longitudinal modes at CLC inhomogeneities.

In order to analyze the influence of the diffraction on a ring structure in the beam, the spectral and spatial characteristics of the CLC lasing in the singlemode regime and at the generation of its three axial modes were studied. In the latter case, a low lasing threshold and the ring-like structure of the beam are typical. The single-mode lasing regime was obtained by creating a defect in the helical structure at the orthogonal orientation of substrates.

In Fig. 5, $a$, the transmission spectra obtained for the dye-doped CLC at mutually orthogonal orientations of directors at the substrates (curve 1) and at their parallel orientations (curve 2) are shown. One can see that the texture of CLC with the orthogonal 

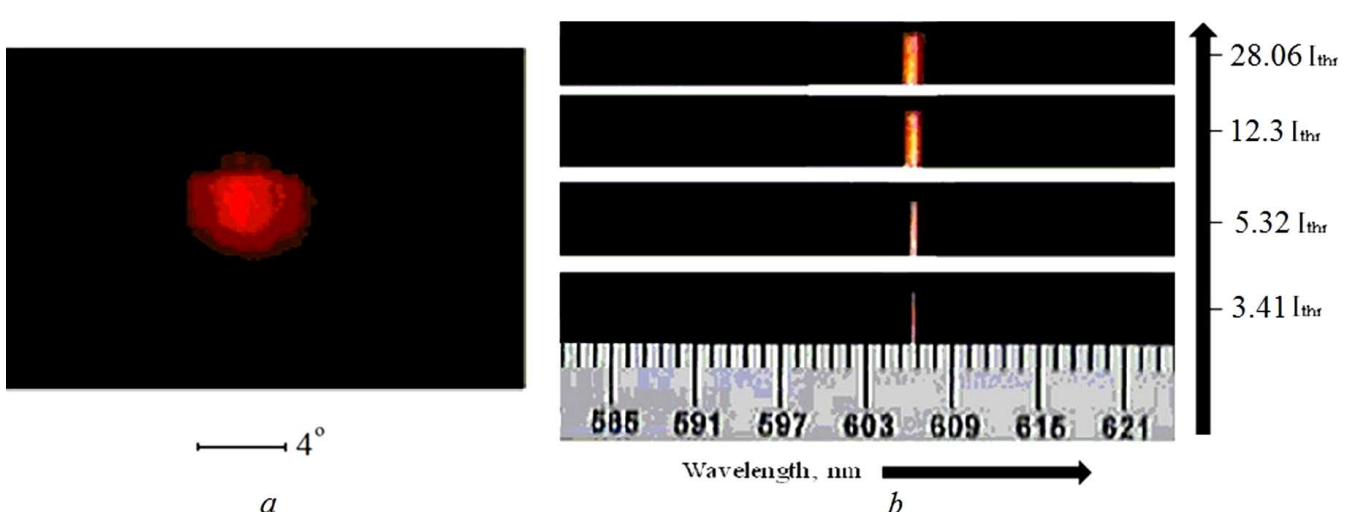

Fig. 6. Angular divergence and generation spectra of a CRC laser with orthogonal director orientations at the substrates; the laser beam cross-section $(a)$, generation spectra for a variation of excitation intensities (b). The layer thickness equals $45 \mu \mathrm{m}$

orientation of directors at the substrates is characterized by a lower intensity of the diffraction in the SR band and by a shift of the SR band center by $5 \mathrm{~nm}$ toward long waves. In addition, there is a dip in the SR band for the linear polarization of light, which is a typical manifestation of a defect in the helical structure [20]. Note that the indicated dip in the SR band was registered at the distances more than $100 \mathrm{~nm}$ from the absorption spectrum maximum $(\lambda=540 \mathrm{~nm})$ and the SR band center. Because of a low amplification at the dip wavelength $(\lambda=644 \mathrm{~nm}$; see Fig. 5, a, curve 3), the lasing threshold was not achieved. For this purpose, the SR band was shifted toward the dye fluorescence maximum by varying either the CLC percentage composition or the temperature.

Figure 5, $b$ demonstrates the transmission spectrum of doped CLC with the orthogonal director orientations at the substrates, when the SR band and the dye fluorescence maximum were matched. As one can see, when the SR band approached the dye absorption band, it became deformed, and the dip identifying the defect of a helical structure disappeared. This specific feature of the transmission spectrum did not allowed us to exactly correlate the wavelengths of the dip and the CLC lasing spectrum under available conditions.

In the lasing spectrum of a CLC laser with the given planar texture (Fig. 6, b), only the fundamental longitudinal mode was excited. The generation spectrum width decreased by more than an order of magnitude, reaching some tenths of nanometer. The spatial pattern of lasing in the CLC with mutually crossed orientations of the molecular layers on the substrate surfaces had no ring structure. Only the central kern was observed, and its angular divergence did not exceed $3^{\circ}$. The light scattering threshold in this texture was higher by more than an order of magnitude in comparison with the ordinary planar texture (with parallel director orientations at the substrates) owing to a lower diffraction power of the helical lattice. The active region with a similar behavior was spatially localized in a zone up to $2 \mathrm{~cm}$ in diameter and confined by disclination lines. Beyond this zone, the lasing spectrum had three modes, and the spatial pattern revealed a ring structure. Such peculiarities in the lasing parameters were observed only in the viscous mixtures of cholesterol esters, but they were absent in the case of low-viscous induced cholesterics. A significant lasing threshold enhancement in the texture of steroid CLCs with orthogonal orientations of molecular surface layers can testify that only a limited thickness of the active layer was involved into the lasing.

The observed effect agrees with a theoretical prediction [20] for the lasing on the defect mode, which can emerge as a result of the phase jump, when the orienting substrate is rotated by $90^{\circ}$ around the helix axis. According to theoretical calculations, the conditions for observing this effect arise, when the defect is arranged in the middle of the active layer thickness.

The laser experiment with a defect CLC helical structure made it impossible to explain the ring structure emerging in the CLC laser beam by the influence of the diffraction, since, in the cases of both ordinary and defect planar textures, the beam aperture remained invariant. Thus, the explanation of the ring 
structure in the CLC laser beam, which was proposed in work [23], remains actual. It enables us to assert that the the ring structure in the CLC lasing beam originates from the generation of modes that propagate at discrete angles with respect to the resonator axis. This explanation was confirmed in work [29], in which a precision measurement of the wavelengths of the CLC lasing at an angle of $21^{\circ}$ with respect to the normal and at the center of the ring structure showed a difference of about $1.9 \mathrm{~nm}$ between them, which undoubtedly rejects the diffraction model of ring formation.

\section{Conclusions}

1. A defect can arise in the helix of CLCs created by viscous mixture of cholesterol esters at the mutually orthogonal director orientations at the orienting substrates. The defect manifests itself as a characteristic dip in the SR band.

2 . The single-mode lasing can be invoked and maintained, under multiple threshold pumping, when CLC directors are oriented mutually orthogonal at the orienting substrates. This method considerably improves the spectral purity and the angular divergence of radiation emitted by a CRC laser.

3. The interrelation between the spectral and spatial characteristics of the lasing in steroid CLCs can be formulated as follows: the ring structure in the laser radiation is associated with the generation of several discrete modes and disappears in the singlemode generation regime. Whence it follows that the ring structure in the CRC laser radiation corresponds to ring modes emerging due to the scattering of longitudinal radiation modes in the CRC.

The work was supported by the grant of the President of Ukraine (project Fr0/127-2017 of the State Fund for Fundamental Research) and the Target Program of the Presidium of the National Academy of Sciences of Ukraine (project VTs-188).

1. I.P. Ilchishin, E.A. Tikhonov, V.G. Tishchenko, M.T. Shpak. Generation of a tunable radiation by impurity cholesteric liquid crystals. JETP Lett. 32, 27 (1980).

2. I.P. Ilchishin, A.G. Kleopov, E.A. Tikhonov, M.T. Shpak. Stimulated tunable radiation in an impurity cholesteric liquid crystal. Bull. Acad. Sci. USSR. Phys. Ser. 45, 13 (1981).

3. H. Kogelnik, S.V. Shank. Coupled-wave theory of distributed feedback lasers. J. Appl. Phys. 43, 2327 (1972).
4. N.V. Kukhtarev. Cholesteric liquid crystal laser with distributed feedback. Sov. J. Quant. Electron. 8, 774 (1978).

5. E. Yablonovitch. Inhibited spontaneous emission in solid state physics and electronics. Phys. Rev. Lett. 58, 2059 (1987).

6. S. John. Strong localization of photons in certain disordered dielectric superlattices. Phys. Rev. Lett. 58, 2486 (1987).

7. I.P. Ilchishin, E.A. Tikhonov, A.V. Tolmachev, A.P. Fedoryako, M.T. Shpak, Harmonic distortion of the induced helical structure of the nematic liquid crystal detected by the distributed feedback laser. Mol. Cryst. Liq. Cryst. 191, 35(1990).

8. J.P. Dowling, M. Scalora, M.J. Bloemer, C.M. Bowden. The photonic band edge laser: A new approach to gain enhancement. J. Appl. Phys. 75, 1896 (1994).

9. V.I. Kopp, B. Fan, H.K.M. Vithana, A.Z. Genak. Lowthreshold lasing at the edge of a photonic stop band in cholesteric liquid crystals. Opt. Lett. 23, 1707 (1998).

10. I P. Ilchishin, E.A. Tikhonov. Dye-doped cholesteric lasers: Distributed feedback and photonic bandgap lasing models. Progr. Quant. Electron. 41, 1 (2015).

11. A.F. Munoz, P. Palffy-Muhoray, B. Taheri. Ultraviolet lasing in cholesteric liquid crystals. Opt. Lett. 26, 804 (2001).

12. J. Schmidtke, W. Stille, H. Finkelmann, S.T. Kim. Laser emission in a dye doped cholesteric polymer network. Adv. Mater. 14, 746 (2002).

13. L.-J. Chen, J.-D. Lina, C.-R. Lee. An optically stable and tunable quantum dot nanocrystal-embedded cholesteric liquid crystal composite laser. J. Mater. Chem. C 2, 4388 (2014).

14. A. Chanishvili, G. Chilaya, G. Petriashvili, R. Barberi, R. Bartolino, G. Cipparrone, A. Mazzulla, R. Gimenez, L. Oriol, M. Pinol. Widely tunable ultraviolet-visible liquid crystal laser. App. Phys. Lett. 86, 051107 (2005).

15. I.P. Ilchishin. Optimizing energy output and angular divergence of a DFB laser with cholesteric liquid crystal. Bull. Russ. Acad. Sci. Phys. 60, 494 (1996).

16. K. Dolgaleva, S.K.H. Wei, S.G. Lukishova, Sh.H. Chen, K. Schwertz, R.W. Boyd. Enhanced laser performance of cholesteric liquid crystals doped with oligofluorene dye. J. Opt. Soc. Am. 25, 1496 (2008).

17. H. Coles, S. Morris. Liquid-crystal lasers. Nat. Photonics 4, 676 (2010).

18. G.E. Nevskaya, S.P. Palto, M.G. Tomilin. Microlasers on liquid crystals. Sov. J. Opt. Techn. 77, 13 (2010).

19. R. Bartolino, L.M. Blinov. Liquid crystal microlasers (introductory notes). In Liquid Crystal Microlasers. Edited by L.M. Blinov, R. Bartolino (Transworld Research Network, 2010).

20. V.A. Belyakov, S.V. Semenov. Optical defect modes in chiral liquid crystals. J. Exper. Theor. Phys. 112, 694 (2011). 
21. Yu.V. Denisov, V.A. Kizel, E.P. Sukhenko. Investigation of ordering of the mesophase of cholesteric liquid crystals on basis of their optical parameters. Zh. Èksp. Teor. Fiz. 71, 679 (1976) (in Russian).

22. H.P. Preiswerk, M. Lubanski, S. Gnepf, F.K. Kneubuhl. Group theory and realization of a helical distributed feedback laser. IEEE J. Quant. Electron. QE-19, 1452 (1983).

23. I.P. Ilchishin, E.A. Tikhonov, M.T. Shpak. Peculiarities of the spatial distribution of the lasing of a distributed feedback laser based on cholesteric liquid crystals. Ukr. J. Phys. 33, 10 (1988).

24. V.I. Kopp, Z.Q. Zang, A.Z. Genack. Lasing in chiral photonics structures. Progr. Quant. Electron. 27, 369 (2003).

25. M.V. Bondar, O.V. Przhonska, E.A. Tikhonov, N.M. Fedotkina. Thermooptics for the doped elastomers. Techn. Phys. 56, 2465 (1986).

26. I.P. Ilchishin, E.A. Tikhonov, M.T. Shpak. Damage to the planar texture of absorbing cholesteric liquid crystals by pulsed laser radiation. Sov. J. Quant. Electron. 17, 1567 (1987).

27. S.M. Arakelyan, Yu.S. Chilingaryan. Nonlinear Optics of Liquid Crystals (Nauka, 1984) (in Russian).

28. B.P. Stoicheff, A. Szabo. Interference rings in ruby beams. Appl. Opt. 2, 811 (1963).
29. S.P. Palto, N.M. Shtykov, B.A. Umansky, M.I. Barnik, L.M. Blinov. General properties of lasing effect in chiral liquid crystals. Opto-Electron. Rev. 14, 323 (2006).

Received 21.03.18. Translated from Ukrainian by O.I. Voitenko

\author{
І.П. Ілъчишин, Є.О.Тихонов, Т.В. Микитюк
}

СПЕКТРАЛЬНО-ПРОМЕНЕВІ ОСОБЛИВОСТІ ВИПРОМІНЮВАННЯ ЛАЗЕРА НА ХОЛЕСТЕРИЧНИХ РІДКИХ КРИСТАЛАХ

$\mathrm{P}$ е $з$ ю м е

Досліджено спектральні-променеві характеристики випромінювання лазера на брегівській структурі холестеричних рідких кристалів (ХРК) при зміні планарної орієнтації. Виявлено, що в XРК, утворених трикомпонентною сумішшю в'язких ефірів холестерину при ортогональній взаємній орієнтації директорів ХРК на підкладках, виникає дефект спіральної структури. Цей дефект проявляється у вигляді локального провалу в смузі селективного відбивання (CB), що узгоджується з поведінкою дефектної моди фотонного кристала. За наявності такого дефекту в спіральній структурі відбувається селекція поздовжніх мод з індексами $N= \pm 1$, при якій реалізується одномодовий режим генерації. Встановлено, що просторова кільцева структура випромінювання такого лазера виникає при генерації вищих поздовжніх мод. 